\title{
PENGARUH PEMBERIAN ZAT PERANGSANG TUMBUH ROOTONE-F TERHADAP PERTUMBUHAN SETEK AKAR SUKUN (Artocarpus altilis Parkinson Fosberg)
}

\author{
Yopi Ramadani, Setiono \\ Program Studi Agroteknologi Fakultas Pertanian Universitas Muara Bungo \\ yopiramadani35@gmail.com \\ Artikel Diterima 18 November 2020, disetujui 10 Januari 2021
}

ABSTRAK

Percobaan ini bertujuan untuk mengetahui pengaruh pemberian zat perangsang tumbuh Rootone- $F$ terhadap ersentase tumbuh setek akar tanaman sukun (Artocarpus altilis Parkinson Fosberg). Percobaan ini dilaksanakan di lahan praktik SMK Negeri 9 Tebo Desa Suo Suo, Kecamatan Sumay, Kabupaten Tebo, Provinsi jambi. Ketinggian tempat 101 mdpl, dengan dengan rata-rata curah hujan $305,83 \mathrm{~mm} /$ tahun, dengan suhu udara antara $27^{\circ}-32^{\circ} \mathrm{C}$, dan jenis Ultisol (BPS,2010). Percobaan ini dilaksanakan 3 bulan, mulai tanggal 2 Januari sampai 3 April 2020.

Percobaan ini menggunakan Rancangan Acak Kelompok (RAK) dengan perlakuan yaitu : K0 (tanpa konsentrasi rootone $f$ ), K1 (rootone $f 200 \mathrm{mg} /$ liter air), K2 (rootone $f 300$ $\mathrm{mg} / \mathrm{liter}$ air), K3 (rootone $f 400 \mathrm{mg} / \mathrm{liter}$ air), $\mathrm{K} 4$ (rootone $f 500 \mathrm{mg} / \mathrm{liter}$ air). Adapun parameter yang diamati pada percobaan ini adalah persentase setek hidup, persentase setek bertunas, waktu awal bertunas, jumlah tunas, jumlah calon tunas. Data yang diperoleh dari pengamatan terakhir dianalisis dengan menggunakan sidik ragam (anova), bila hasil analisis berpengaruh nyata maka dilanjutkan dengan uji Duncan New Multiple Range Test (DNMRT) pada taraf $5 \%$.

Hasil percobaan menunjukkan bahwa konsentrasi Rootone $\mathrm{F}$ berpengaruh nyata terhadap persentase setek hidup, persentase setek bertunas, waktu awal bertunas, jumlah tunas, jumlah calon tunas.

Kata Kunci : Rootone F, Setek Akar Sukun, Pertumbuhan dan Hasil

\section{PENDAHULUAN}

Tanaman sukun (Artocarpus altilis Parkinson Fosberg) adalah salah satu tanaman serbaguna yang banyak dibudidayakan oleh masyarakat Indonesia yang tersebar dari Aceh hingga Papua. Jenis ini menghasilkan buah yang memiliki kandungan gizi yang tinggi sehingga sangat potensial untuk dikembangkan sebagai alternatif sumber makanan pokok ( Susilawati dan Adinugraha, 2014). Berkurangnya pasokan bahan makanan pokok dan mahalnya harga bahan-bahan pokok, menjadikan buah sukun sebagai salah satu sumber pangan alternatif yang sangat berguna (Pitojo, 1995).

Budidaya tanaman sukun di masyarakat Indonesia telah berlangsung sejak lama, walaupun hanya sebagai tanaman sampingan di pekarangan atau kebun. Hasil buahnya hanya dijadikan sebagai makanan ringan/ tambahan yang diolah secara tradisional atau dijual ke pasar. Mengingat daerah sebarannya yang luas, maka buah sukun sangat potensial dijadikan sebagai salah satu sumber bahan makanan pokok bagi masyarakat. Akan tetapi upaya pengembangan jenis tanaman sukun di masyarakat seringkali menghadapi permasalahan yaitu :

Kurangnya informasi tentang teknik pembibitan tanaman sukun, sehingga masyarakat masih sering menghadapi kesulitan dalam menghasilkan bibit sukun yang baik dengan jumlah yang memadai. Sebagian para petani produsen bibit masih menggunakan cara-cara sederhana atau seadanya, sehingga tingkat 
keberhasilannya relatif rendah dan jumlah bibit yang dihasilkan relatif sedikit,

Penyebar luasan informasi tentang kandungan gizi buah dan teknik pengolahan buah sukun kepada masyarakat masih kurang. Pengolahan buah sukun oleh masyarakat masih terbatas untuk beberapa macam makanan saja, sebagai makanan ringan. Dengan adanya diversifikasi teknologi pengolahan hasil buah sukun diharapkan akan dapat memberikan nilai tambah bagi masyarakat dan menjadi salah satu peluang meningkatkan pendapatan masyarakat (Departemen Kehutanan, 2003).

Setek seringkali mengalami kegagalan dengan tidak tumbuhnya akar. Salah satu usaha untuk mengatasi kegagalan dalam pertumbuhan akar pada setek adalah dengan memberikan Zat Pengatur Tumbuh (ZPT). Dalam mengaplikasikan ZPT perlu diperhatikan ketepatan dosis, karena jika dosis terlampau tinggi bukannya memacu pertumbuhan tanaman tetapi malah menghambat pertumbuhan tanaman dan menyebabkan keracunan pada seluruh bagian tanaman (Didiet, 2009). Menurut (Carsono, 2008) permasalahan yang ada dalam pembiakan tanaman dengan setek adalah sulitnya pembentukan akar, dan usaha untuk mempercepat terbentuknya akar dapat dilakukan dengan menggunakan zat pengatur tumbuh (ZPT). Zat pengatur tumbuh tanaman yang dihasilkan oleh tanaman disebut fitohormon, sedangkan yang sintesis disebut zat pengatur tumbuh sintetik.

Menurut Adinugraha dan Kartikawati, (2003) untuk mempercepat pembentukan akar pada tanaman, dapat digunakan zat pengatur tumbuh buatan yang diberi secara eksogen (dari luar). Salah satu zat pengatur tumbuh dari jenis auksin yang digunakan untuk membantu mempercepat keluarnya akar pada setek adalah ZPT Rootone F, yang mengandung beberapa bahan aktif senyawa seperti auksin, NAA dan IBA.
Lama perendaman harus disesuaikan dengan konsentrasi larutan yang digunakan. Lamanya stek dalam larutan zat pengatur tumbuh bertujuan agar penyerapan ZPT berlangsung dengan baik. Perendaman juga harus dilakukan ditempat yang teduh dan lembab agar penyerapan ZPT yang diberikan berjalan teratur, tidak fluktuatif karena pengaruh lingkungan (Daniawati, 2007).

Hasil penelitian Cut dan Ismail (2015) menyatakan bahwa menggunakan Rootone-F menunjukkan bahwa penggunaan konsentrasi $200 \mathrm{mg} / \mathrm{liter}$ air memberikan hasil yang paling optimal untuk pertumbuhan panjang tunas dan jumlah daun stek pucuk jambu air. Hasil penelitian bambu petung hitam menggunakan Rootone-F menunjukkan bahwa penggunaan konsentrasi $400 \mathrm{mg} / \mathrm{l}$ memberikan hasil yang paling optimal untuk pertumbuhan Panjang Akar dan Jumlah Daun (Arinasa et al. 2015). Menurut Yunita (2011), menyatakan bahwa pemberian larutan Rootone-F dengan konsentrasi $100 \mathrm{mg}$, memberikan pengaruh terhadap semua parameter pengamatan dan konsetrasi Rootone-F 100 mg merupakan sumber auksin terbaik untuk merangsang pertumbuhan akar sebanyak 5,83 pada stek markisa. Budianto et al. (2013), menyatakan bahwa perlakuan lama perendaman dengan IBA selama 3 jam memberikan pengaruh secara nyata terhadap parameter Panjang Akar, Jumlah Daun, dan Bobot Kering Akar pada stek tanaman sirih merah.

Berdasarkan uraian diatas penulis tertarik untuk melakukan penelitian mengenai "Pengaruh Pemberian Zat Perangsang Tumbuh Rootone-F Terhadap Pertumbuh Stek Akar Sukun (Artocarpus altilis Parkinson Fosberg)” Rumusan Masalah

1. Apakah Pemberian konsentrasi Rootone- $F$ berpengaruh terhadap pertumbuhan stek akar sukun (Artocarpus altilis Parkinson Fosberg)? 
2. Berapa konsentrasi yang terbaik untuk meningkatkan pertumbuhan stek akar sukun (Artocarpus altilis Parkinson Fosberg)?

\section{Tujuan Penelitian}

Untuk mengetahui pengaruh pemberian konsentrasi Rootone- $F$ yang terbaik terhadap pertumbuhan setek akar sukun (Artocarpus altilis Parkinson Fosberg)

\section{Kegunaan Penelitian}

Hasil penelitian ini diharapkan dapat digunakan sebagai sumber bahan bacaan dan pengayaan bagi mahasiswa tingkat di Universitas Muara Bungo Khusunya di Fakultas Pertanian dan dapat juga dijadikan referensi untuk melakukan penelitian pada budidaya tanaman sukun.

\section{Hipotesis Penelitian.}

1. Diduga pemberian konsentrasi Rootone$F$ berpengaruh terhadap pertumbuhan setek akar sukun (Artocarpus altilis Parkinson Fosberg).

2. Diduga Pemberian konsetrasi Rootone$F$ dengan konsentrasi $400 \mathrm{mg} /$ liter air memberikan pengaruh terbaik terhadap pertumbuhan tanaman sukun (Artocarpus altilis Parkinson Fosberg)

\section{METODE PENELITAN.}

\section{Tempat dan Waktu Penelitian.}

Rencana penelitian ini di laksanakan di Desa Suo-Suo, Kecamatan Sumay, Kabupaten Tebo. Di lahan Praktek SMK N 9 Tebo. Lokasi Penelitian terletak pada ketinggian $70 \mathrm{~m}$ diatas permukaan laut dengan jenis Ultisol (IPB, 2018) Rangkaian kegiatan mulai pada November 2019 sampai januari 2020, dari pengambilan bahan setek Sukun di Desa Suo- Suo Kecamatan Sumay, Kabupaten Tebo Provinsi Jambi.

\section{Bahan dan Alat.}

Bahan setek yang digunakan dalam penelitian ini adalah Akar dari Pohon
Induk Sukun dengan tinggi berkisar $8 \mathrm{M}$ yang memenuhi kriteria kesehatan. Adapun media tanam yang digunakan berupa top soil, pupuk kandang dan pasir. Zat Pengatur Tumbuh Rootone-F, dan Dithane (sebagai anti jamur) digunakan dalam penelitian ini.

Alat yang digunakan adalah sungkup , gunting setek, polybag, ember,sendok, termometer, hand sprayer, timbangan digital, paranet, penggaris, bambu, tali pengikat, meteran, parang, cangkul, pisau, kertas label, kamera untuk mengambil gambar dan alat tulis.

\section{Rancangan Penelitian}

Rancangan percobaan yang digunakan dalam penelitian ini adalah

Rancangan Acak Kelompok (RAK). Perlakuan konsentrasi zat pengatur tumbuh (Rootone-F) yang digunakan dalam penelitian ini yaitu :

$\mathrm{K} 0=$ Tanpa Kosentrasi Rootone- $F$

$\mathrm{K} 1=$ Kosentrasi Rootone-F 200 $\mathrm{mg} / \mathrm{liter}$ air

$\mathrm{K} 2=$ Kosentrasi Rootone $-F \quad 300$ $\mathrm{mg} / \mathrm{liter}$ air

$\mathrm{K} 3=$ Kosentrasi Rootone-F 400 $\mathrm{mg} / \mathrm{liter}$ air

$\mathrm{K} 4=$ Kosentrasi Rootone $-F \quad 500$ $\mathrm{mg} / \mathrm{liter}$ air

Setiap perlakuan terdiri dari 4 ulangan dan setiap ulangan terdiri dari 3 stek. Sehingga jumlah stek yang ditanam adalah

$5 \times 4 \times 3=60$ setek.

\section{HASIL DAN PEMBAHASAN \\ Persentase Setek Hidup (\%)}

Hasil analisis ragam menunjukkan bahwa pemberian zat perangsang tumbuh Rootone-F tidak berpengaruh nyata terhadap persetase setek hidup. Rataan jumlah persentase setek sukun pada masing-masing pengaruh pemberian Rootone-F dapat dilihat pada Tabel 1.

Tabel 1. Rataan Jumlah Persentase Setek Hidup Hasil Pemberian Rootone-F

\section{Perlakuan Pemberian Rootone-F}

$\begin{array}{cc}\text { Rataan } & \text { Rataan (\%) } \\ (\%) & \text { Transformasi } \\ \text { Asli } & \text { Logaritma }\end{array}$




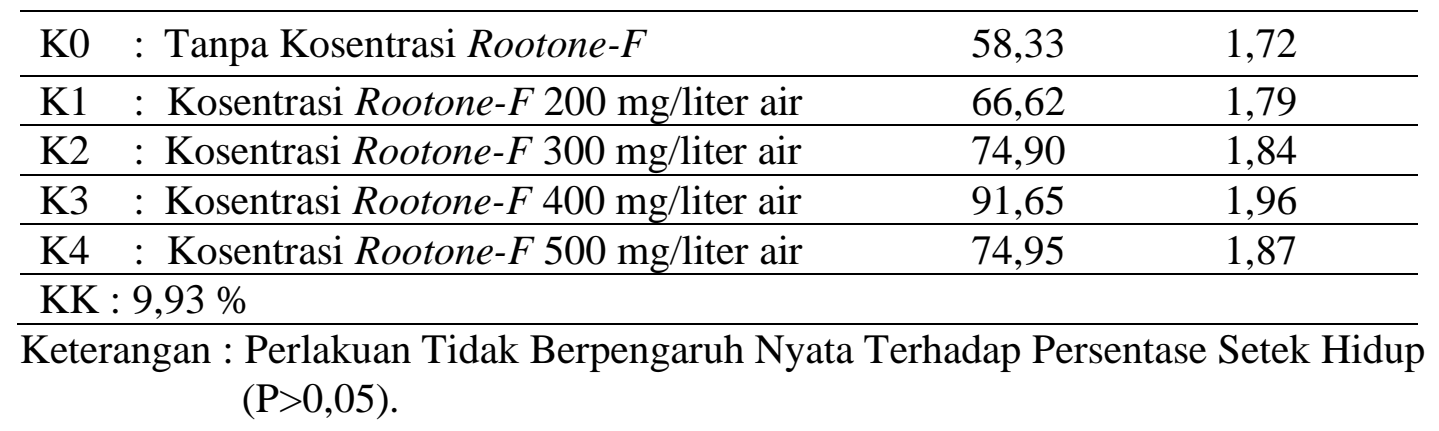

Dari Tabel 1 diatas dapat dijelaskan bahwa pemberian Rootone-F memberikan pengaruh tidak nyata terhadap persentase setek hidup setek sukun. Hal ini disebabkan oleh bahan Setek akar sukun yang bervariasi kondisi dan sudah terlalu tua. Menurut hasil penelitian Mindawati et. . al (2012) bahwa penggunaan hormon Rootone-F dalam pembibitan setek pucuk manglid menghasilkan persentase hidup yang relatif rendah $(<22,68 \%)$. Rendahnya persentase hidup setek disebabkan oleh rendahnya kualitas bahan setek.

Hasil penelitian Wiratama et, al (2015) menyatakan bahwa Pengaruh kombinasi konsentrasi zat pengatur tumbuh Rootone-F dan komposisi media tanam tidak berpegaruh terhadap variabel kekerhasilan setek hidup, jumlah daun, panjang akar dan berat kering total pada setek pucuk merah. Hal ini juga dikuatkan oleh hasil penelitian Riniarti (2014) yang menyatakan Pemberian Rootone-F dengan berbagai konsentrasi tidak memberikan pengaruh yang signifikan terhadap persentase hidup jabon. Pada prinsipnya setiap tanaman memiliki hormon tersendiri yang mampu merangsang pertumbuhan, akan tetapi hormon pada tanaman tersebut jumlahnya terbatas sehingga perlu penambahan hormon perangsang tumbuh agar tanaman mampu tumbuh lebih cepat dan lebih baik.

\section{Persentase Setek Bertunas}

Hasil analisis ragam menunjukkan bahwa pemberian zat perangsang tumbuh Rootone-F tidak berpengaruh nyata terhadap persentase setek bertunas. Rataan jumlah persentase setek bertunas pada masing-masing pengaruh pemberian Rootone-F dapat dilihat pada Tabel 2.

Tabel 2. Rataan Jumlah Persentase Setek Bertunas Hasil Pemberian Rootone-F

\begin{tabular}{|c|c|c|c|}
\hline \multicolumn{2}{|c|}{ Perlakuan Pemberian Rootone-F } & $\begin{array}{c}\text { Rataan } \\
(\%) \\
\text { Asli }\end{array}$ & $\begin{array}{c}\text { Rataan (\%) } \\
\text { Transformasi } \\
\text { Logaritma }\end{array}$ \\
\hline K0 & : Tanpa Kosentrasi Rootone-F & 58,3 & 1,72 \\
\hline K1 & : Kosentrasi Rootone-F $200 \mathrm{mg} /$ liter air & 66,62 & 1,79 \\
\hline $\mathrm{K} 2$ & : Kosentrasi Rootone-F $300 \mathrm{mg} /$ liter air & 74,9 & 1,84 \\
\hline K3 & : Kosentrasi Rootone-F $400 \mathrm{mg} /$ liter air & 91,65 & 1,96 \\
\hline $\mathrm{K} 4$ & : Kosentrasi Rootone-F $500 \mathrm{mg} /$ liter air & 74,95 & 1,87 \\
\hline
\end{tabular}

KK : 9,93\%

Keterangan : Perlakuan Tidak Berpengaruh Nyata Terhadap Persentase Setek Bertunas $(\mathrm{P}>0,05)$.

Dari Tabel 2 diatas dapat dijelaskan bahwa pemberian Rootone-F memberikan pengaruh tidak nyata terhadap persentase bertunas setek sukun. Hal ini disebabkan oleh respon setiap jenis tanaman terhadap hormon perangsang tumbuh yang berbedabeda baik laju penyerapan dan dosis yang diberikan. Hal ini sependapat dengan 
Abidin (1983) dalam Riniarti (2014) bahwa pemberian ZPT yang berlebihan pada tanaman akan menghambat pertumbuhan tanaman. Pendapat ini dikuatkan oleh Wattimena (1987) dalam Riniarti (2014) bahwa respon tanaman atau bagian tanaman terhadap hormon yang diberikan akan berbeda-beda tergantung jenis tanaman, umur, keadaan lingkungan, tingkat perkembangan fisologis terutama kandungan hormon endogen dan unsur hara.

\section{Waktu Awal Bertunas}

Hasil analisis ragam menunjukkan bahwa pemberian zat perangsang tumbuh Rootone-F berpengaruh nyata terhadap hari waktu awal bertunas. Rataan jumlah persentase setek bertunas pada masingmasing pengaruh pemberian Rootone-F dapat dilihat pada Tabel 3.

Tabel 3. Rataan Jumlah Hari Waktu Awal Bertunas Hasil Pemberian Rootone-F

Perlakuan Pemberian Rootone-F

\section{Hasil Rataan}

\begin{tabular}{llll}
\hline K0 & : Tanpa Kosentrasi Rootone- $F$ & 31,32 & a \\
\hline K1 & : Kosentrasi Rootone $-F 200 \mathrm{mg} /$ liter air & 29,00 & b \\
\hline K2 & : Kosentrasi Rootone $-F 300 \mathrm{mg} /$ liter air & 26,45 & c \\
\hline K3 & : Kosentrasi Rootone $-F ~ 400 \mathrm{mg} /$ liter air & 19,77 & d \\
\hline K4 & : Kosentrasi Rootone $-F 500 \mathrm{mg} /$ liter air & 32,77 & a \\
\hline KK : 4,63\%
\end{tabular}

Keterangan : Angka-Angka yang diikuti huruf-huruf kecil yang sama pada kolom sama tidak berbeda nyata pada uji DMRT Taraf 5\% (P>0,05).

Tabel 3. menunjukkan bahwa hari waktu awal bertunas sangat dipengaruhi oleh perlakuan konsentrasi pemberian Rootone-F. Hasil penelitian menujukkan bahwa pemberian Rootone-F dengan konsentrasi $400 \mathrm{mg} / \mathrm{liter}$ air merupakan Konsentrasi terbaik. Tabel diatas menunjukkan bahwa perlakuan K0 tidak berbeda dengan $\mathrm{K} 4$, namun berbeda dengan $\mathrm{K} 1, \mathrm{~K} 2$ dan $\mathrm{K} 3$.

Menurut Zuryanisa (2006), salah satu usaha untuk meningkatkan keberhasilan setek tunas adalah dengan penggunaan zat pengatur tumbuh (ZPT) yang tepat. Hasil penelitian bambu petung hitam menggunakan Rootone-F menunjukkan bahwa penggunaan konsentrasi $400 \mathrm{mg} / \mathrm{l}$ memberikan hasil yang paling optimal untuk pertumbuhan panjang akar dan jumlah daun (Arinasa $e t$ al. 2015). Di perdalam juga dengan hasil penelitian Sitawati dan Ayuningtyas (2019) yang menyatakan bahwa hasil Analisis ragam menunjukan bahwa perlakuan panjang bahan setek tanaman dan pemberian ZPT Rootone-F menyatakan adanya interaksi nyata pada parameter pengamatan waktu muncul tunas pada tanaman Firespike.

\section{Jumlah Tunas (Buah)}

Menurut hasil penelitian Sri Rahayu et.,al (2002) dengan pemberian Pada konsentrasi 18\%-20\% memperlihatkan pertumbuhan paling baik pada parameter jumlah tunas, jumlah daun, luas daun dan jumlah akar. berbagai konsentrasi filtrat umbi bawang merah dengan penambahan Rootone-F. Dalam mangaplikasikan Rootone-F perlu diperhatikan ketepatan dosis, karena jikalau dosis terlampau tinggi bukannya memacu pertumbuhan tanaman tetapi malah menghambat pertumbuhan tanaman dan menyebabkan keracunan pada seluruh bagian tanaman (Abidin, 2003)

Hasil analisis ragam menunjukkan bahwa pemberian zat perangsang tumbuh Rootone-F berpengaruh nyata terhadap jumlah tunas. Rataan jumlah tunas pada masing-masing perlakuan pemberian Rootone-F dapat dilihat pada Tabel 4. 
Tabel 4. Rataan Jumlah Tunas Hasil Pemberian Rootone-F

\begin{tabular}{|c|c|c|c|c|}
\hline Perlakuan Pemberian Rootone-F & $\begin{array}{c}\text { Rataan } \\
\text { (Bh) } \\
\text { Asli }\end{array}$ & DMRT & $\begin{array}{c}\text { Rataan } \\
\text { (Bh) } \\
\text { Trasformasi } \\
\text { Logaritma }\end{array}$ & DMRT \\
\hline K0 : Tanpa Kosentrasi Rootone-F & 1,65 & $b$ & 0,42 & $\mathrm{~b}$ \\
\hline $\begin{array}{l}\text { K1 : Kosentrasi Rootone-F } 200 \\
\text { mg/liter air }\end{array}$ & 1,62 & b & 0,41 & $\mathrm{~b}$ \\
\hline $\begin{array}{l}\text { K2 : Kosentrasi Rootone-F } 300 \\
\text { mg/liter air }\end{array}$ & 1,4 & b & 0,37 & $\mathrm{~b}$ \\
\hline $\begin{array}{l}\text { K3 : Kosentrasi Rootone-F } 400 \\
\text { mg/liter air }\end{array}$ & 2,65 & a & 0,56 & a \\
\hline $\begin{array}{l}\text { K4 : Kosentrasi Rootone-F } 500 \\
\text { mg/liter air }\end{array}$ & 1,075 & $\mathrm{~b}$ & 0,32 & $\mathrm{~b}$ \\
\hline
\end{tabular}

KK : $17,24 \%$

Keterangan : Angka-Angka yang diikuti huruf-huruf kecil yang sama pada kolom $\quad$ yang sama tidak menjadi perbedaan pada uji DMRT Taraf 5\% (P>0,05).

Tabel 4. menunjukkan bahwa jumlah tunas setek sukun sangat dipengaruhi oleh perlakuan konsentrasi pemberian Rootone-F. Hasil penelitian menujukkan bahwa pemberian Rootone-F dengan konsentrasi $400 \mathrm{mg} / \mathrm{liter}$ air merupakan konsentrasi terbaik. Tabel diatas menunjukkan bahwa perlakuan $\mathrm{K} 0$ tidak berbeda dengan $\mathrm{K} 1, \mathrm{~K} 2$ dan $\mathrm{K} 4$, namun berbeda dengan $\mathrm{K} 3$.

\section{Jumlah Calon Tunas (Buah)}

Hasil analisis ragam menunjukkan bahwa pemberian zat perangsang tumbuh Rootone-F tidak berpengaruh nyata Tabel 5. Rataan Jumlah Calon Tunas Hasil Pemberian Rootone-F

\begin{tabular}{llcc}
\hline Perlakuan Pemberian Rootone-F & $\begin{array}{c}\text { Rataan } \\
(\mathbf{B h}) \\
\text { Asli }\end{array}$ & $\begin{array}{c}\text { Rataan (Bh) } \\
\text { Transformasi } \\
\text { Logaritma }\end{array}$ \\
\hline K0 : Tanpa Kosentrasi Rootone-F & 1,77 & 0,43 \\
\hline K1 : Kosentrasi Rootone-F $200 \mathrm{mg} /$ liter air & 1,75 & 0,43 \\
\hline K2 : Kosentrasi Rootone-F $300 \mathrm{mg} /$ liter air & 2,00 & 0,46 \\
\hline $\mathrm{K} 3 \quad$ : Kosentrasi Rootone-F $400 \mathrm{mg} /$ liter air & 3,11 & 0,61 \\
\hline $\mathrm{K} 4 \quad:$ Kosentrasi Rootone-F $500 \mathrm{mg} /$ liter air & 1,75 & 0,43 \\
\hline
\end{tabular}

KK : 9,93\%

Keterangan : perlakuan tidak berpengaruh nyata terhadap jumlah calon tunas $(\mathrm{P}>0,05)$.

Dari Tabel 5 diatas dapat dijelaskan bahwa pemberian Rootone-F tidak memberikan pengaruh nyata terhadap jumlah calon
Pemberian Rootone-F dengan konsentrasi $400 \mathrm{mg} / \mathrm{liter}$ air menunjukkan bahwa pemberian ZPT paling berpengaruh terhadap jumlah tunas. Sedangkan pada perlakuan pemberian Rootone-F 500 $\mathrm{mg} / \mathrm{liter}$ air mengalami penurunan jumlah tunas. Kekurangan konsentrasi tidak akan memberikan dampak signifikan dan kelebihan konsentrasi malah akan menjadi racun bagi tanaman.

terhadap jumlah calon tunas. Rataan jumlah calon tunas pada masing-masing pengaruh pemberian Rootone-F dapat dilihat pada Tabel 5. 
Dengan adanya penyerapan hara Makro, mikro serta zat pengatur tumbuh eksogen melalui daun maka dapat memenuhi kebutuhan hidup tanaman baik untuk pertumbuhan dan perkembangan tanaman (Salisbury dan Ross ,1995. Penambahan Zat Pengatur Tumbuh Rootone-F yang mengandung senyawa auksin dengan konsentrai tertentu ditujukan agar dapat memacu inisiasi akar. Perakaran yang baik akan mendukung terjadinya proses penyerapan hara, air untuk pertumbuhan. Selain itu auksin dapat menstimulasi terjadi perpanjang sel pucuk tanaman Artanti , (2007) dalam Tarigan, (2017).

\section{DAFTAR PUSTAKA}

Abidin. 2003. Pengaruh Komposisi Media Tanam dan Konsentrasi Ga3 Terhadap Inisiasi dan Pertumbuhan Tunas Sansevieria Trifaciata Prain 'Laurentii' Departemen Agronomi Dan Hortikultura Fakultas Pertanian Institut Pertanian Bogor.

Adinugraha dan Kartikawati. 2003. Litbang Sukun dan Perannya Dalam Mendukung Gerakan Rehabilitasi Hutan dan Lahan. Yogyakarta.

Adinugraha, H, A. 2011. Pengaruh Umur Pohon Induk, Umur Tunas Dan Jenis Media Terhadap Pertumbuhan Setek Pucuk Sukun.

Andiani,N. 2012. Pengaruh Komposisi Media Tanam dan Konsentrasi Ga3 Terhadap Inisiasi dan Pertumbuhan Tunas Sansevieria Trifaciata Prain 'Laurentii' Departemen Agronomi Dan Hortikultura Fakultas Pertanian Institut Pertanian Bogor.

Arinasa W. Wujianto L. Daus M. 2015. Pedoman Penggunaan Hormon Tumbuh Akar Pada Pembibitan Bambu Petuk. Departemen Kehutanan Direktorat Jenderal Reboisasi dan Rehabilitasi Lahan.

Ardian. 2013. Perbanyakan tanaman melalui setek batang mini tanaman singkong (Manihot esculenta Crantz.) untuk pemulia tanaman dan produsen benih. Jurnal Penelitian Pertanian Terapan. 24$32 \mathrm{p}$.

Batubara, R. 2002. Pemanfaatan bambu di Indonesia. Skripsi. Fakultas Pertanian Universitas Sumatera Utara. Medan

Budianto E. A, Kaswan Badami, Ahmad Arsyadmunir. 2013. Pengaruh Kombinasi Macam Zpt Dengan Lama Perendaman Yang Berbeda Terhadap Keberhasilan Pembibitan Sirih Merah (Piper crucatum Ruiz \& Pav) SecaraSetek. Jurnal Penelitian Agrovigor Volume 6 No. 2 ISSN 1979 5777. Fakultas Pertanian Universitas Trunojoyo Madura.

Carsono, N. 2008. Peran Pemulia Tanaman Dalam Meningkatkan Produksi di Indonesia. Dalam Seminar Agriculture sciences Tokyo

Cut, M dan J, Ismail. 2015. Pengaruh Konsentrasi Dan Lama Perendaman Rootone-F Terhadap Pertumbuhan Setek Pucuk jambu Air (Syzygium semaragense) Pada Media Oasis.

Darliana,I. 2005. Pengaruh Konsentrasi Rootone-FTerhadap Pertumbuhan Setek Cabang Buah Tanaman Lada (Pipernigrum L.) Kultivar Bulok Belantung. Jurusan Agroteknologi Fakultas pertanian UNBAR.

Daniawati,H. 2007. Pengaruh Panjang Dan Bentuk Potongan Pangkal setek Terhadap Pertumbuhan Semai Gamal (Gliricidia Sepium Jacq Steud.). Fakultas Kehutanan. Universitas Muhammadyah Malang. 
Departemen Kehutanan, 2003. Budidaya Pohon Serbaguna (MPTS) Sukun (ArtocarpuscommunisForst). Ditjen Reboisasi dan Rehabilitasi Lahan Direktorat Reboisasi. Jakarta.

Didiet, S. 2009. Pemanfaatan Buah Sukun sebagai Makanan Alternatif Pengganti Beras. Puslitbang Indhan Balitbang Dephan, Jakarta.

Febriana,S. 2009. Pengaruh Konsentrasi Zat Pengatur Tumbuh Dan Panjang Setek Terhadap Pembentukan Akar Dan Tunas Pada Setek Apokad (Persea Americana Mill.) Program Studi Hortikultura Fakultas Pertanian Institut Pertanian Bogor

Goenawan, R.C.C. 2006. Pengaruh Induksi Suhu Dan Metode Aplikasi Zat Pengatur Tumbuh Rootone-F Terhadap Induksi Akar Dan Tunas Setek Dadap Merah (Erythrina Crystagalli), Program Studi Pemuliaan Tanaman Dan Teknologi Benih Fakultas Pertanian Institut Pertanian Bogor.

Handayani, T. 2006. Pembibitan secara setek-mini tanaman melati (Jasminum Sambac (L) Aiton). Jurnal Balai Teknologi Lingkungan. $21-25 \mathrm{p}$.

Harjadi, S. 2009. Zat Pengatur Tumbuh. Buku. Penebar Swadaya. Jakarta. $76 \mathrm{p}$.

Khasbiyanto. 2008. Studi Pertumbuhan Tunas Bibit Setek Pangkas dan Kemampuan Berakar Setek Balangeran (Shorea Balangeran Burck) Dalam Sistem Pemangkasan Bergulir. Departemen Silvikultur Fakultas Kehutanan Institut Pertanian Bogor.

Kurniastuti. 2016. Pengaruh Konsentrasi Rootone-FTerhadap Pertumbuhan Setek Cabang Buah Tanaman Lada (Pipernigrum L.) Kultivar Bulok http://ojs.umb-bungo.ac.id/index.php/saingro/index

Belantung. Jurusan Agroteknologi Fakultas pertanian UNBAR.

Meda, 2013,. Tehnik Pembibitan dan Perbanyakan Vegetatif Tanaman Buah. World Agroforestry Centre (ICRAF) dan Winrock International. Bogor.

Mindawati, N. Rohandi A. Sudomo, A. 2012. Penggunaan Zat Pengatur Tumbuh Pada Setek Pucuk Manglid Bi Rootone-F (Manglietia glauca). Balai Penelitian Teknologi Agroforestry.

Pitojo. 1995. Taksonomi Tanaman Buah Indonesia.

http://haruting.blogspot.com

(Diakses pada tanggal, 18 juni 2020, pukul 20.30)

Prasetyaningsih D. Dwi dan Sitawati. 2019.

Pengaruh Posisi Penanaman dan Pemberian zat Pengatur Tumbuh Terhadap Keberhasilan Pertumbuhan Setek Batang Tanaman Lee Kwan Yew (Vernonia elliptica). http://protan.studentjournal.ub.ac.id /index.php/protan/article/view/997/ 1018. Diakses Oktober 2019.

Prastyo, 2016. Pengaruh Pemberian Zpt (Rootone-F) Terhadap

Pertumbuhan zaitun (Olea europaea L.), Blume. Departemen Silvikultur Fakultas Kehutanan Institut Pertanian Bogor

Puspitasari,R. 2008. Pertumbuhan Setek Pucuk Tanaman Jarak Pagar ( Jatropha curcas L ) Pada Berbagai Kombinasi Media dan Zat pegatur Tumbuh. 59 Departemen Biologi, Fakultas Matematika dan Ilmu Pengetahuan Alam, Institut Pertanian Bogor

Puspita, P.2011.Pengaruh Pengemasan Dan SuhuTerhadap Daya Simpan Buah Naga Super Merah (Hylocereus 
Costaricensis). Departemen

Agronomi dan Hortikultura.

Fakultas Pertanian Institut

Pertanian Bogor.

Ragone, D. 1997. Bread Fruit: Artocarpus Altilis (Parkinson) Fosbang. Promuting the Conservation and Used of Uderutilize and Neglected Crops lo International Plant Ganatic Resources Institute Rome. Italy

Raharjo, K.D. 2004. Pengaruh Pemberian IBA, NAA, Air Kelapa dan Arang Aktif terhadap Induksi Akar Azadirachta excelsa (Jack) $M$. Jacobs secara In Vitro [skripsi]. Bogor : Fakultas Kehutanan. Institut Pertanian Bogor.

Rahmawati,B. Edwi Mahajoeno.2010. Variasi morfologi, isozim dan kandungan vitamin $\mathrm{C}$ pada varietas buah naga. Program Studi Biosains Program Pascasarjana Universitas Sebelas Maret Surakarta.

Riniarti, M. Indriyanto. Putra, F. 2014. Keberhasilan Hidup Setek Pucuk Jabon (Anthocephalus cadamba) Dengan Pemberian Beberapa Konsentrasi Rootone-F. Jurusan Kehutanan, Fakultas Pertanian, Universitas Lampung

Rochimi, D. K. 2008. Produksi Bibit Biti (Vitex cofassus Reinw. ex Blume) melalui Pembiakan Vegetatif. [skripsi]. Bogor : Fakultas Kehutanan Institut Pertanian Bogor.

Pitojo, S, 1995. Budidaya Sukun. Penerbit Kanisius, Yogyakarta

Puspita, P.2011.Pengaruh Pengemasan Dan SuhuTerhadap Daya Simpan Buah Naga Super Merah (Hylocereus Costaricensis). Departemen Agronomi dan Hortikultura. Fakultas Pertanian Institut Pertanian Bogor.
Puspitasari,R. 2008. Pertumbuhan Setek Pucuk Tanaman Jarak Pagar ( Jatropha curcas L ) Pada Berbagai Kombinasi Media dan Zat pegatur Tumbuh.

Prastyo. 2006. Pengaruh Bahan Setek dan Dosis Zat Pengatur Tumbuh Rootone-F Terhadap Keberhasilan Setek Euphorbia milii. Program Studi Pemuliaan Tanaman dan Teknologi Benih. Fakultas Pertanian. Institut Pertanian Bogor.

Sunandar, R. 2006. Pengaruh Induksi suhu dan konsentrasi Rootone-F dengan Metode Perendaman terhadap pembentukan Akar dan Tunas Setek Akar Sonokeling (Dalbergia latifolia Roxb.). Departemen Agronomi Dan Hortikultura Fakultas Pertanian Institut Pertanian Bogor.

Susilawati, S dan Adinugraha, H, A. 2014. Variasi Kandungan Kimia Tanaman Sukun Dari Beberapa Populasi Di Indonesia Sebagai Sumber Pangan Dan Obat.

Sri Rahayu, Y. Budipramana Lukas, S. Mayasari, E. 2002. Pengaruh Pemberian Filtrat Bawang Merah dengan Berbagai Konsentrasi dan Rootone-F terhadap Pertumbuhan Setek Batang Tanaman Jambu Biji (Psidium guajava L). Jurusan Biologi, Fakultas Matematika dan Ilmu Pengetahuan Alam Universitas Negeri Surabaya

Sitawati. Dwi, P. 2019. Pengaruh Konsentrasi Zat Pengatur Tumbuh Dan Panjang Setek Terhadap Pembentukan Akar Dan Tunas Pada Setek Lee Kwan Yew (Vernonia eliptica.) Program Studi Hortikultura Fakultas Pertanian Institut Pertanian Bogor

Sitawati. Ayuningtyas, F, A. 2019. Pengaruh Root Growth Rootone-F dan 
Panjang Setek terhadap Efisiensi Penggunaan Bahan Setek Tanaman Firespike (Odontonema strictum). Department of Agronomy, Faculty of Agriculture, Brawijaya University

Tarigan. 2017. Pengaruh Konsentrasi Rootone-F Terhadap Persentase Tumbuh Setek Lemon (Citrus limon). Jurusan Agronomi Fakultas Pertanian UNPAD.

Wiratama, G. Hidayat, F. M, Deselina. 2015. Keragaan Setek Pucuk Syrygium oleina terhadap Pemberian Zat Pengatur Tumbuh Rootone-F dan Komposisi Media Tanam. Jurusan Kehutahan Fakultas Pertanian UNIB.
Widiarsih, N. H.J. M. Roshetko dan G. E. S. Manurung. 2008. Tehnik Pembibitan dan Perbanyakan Vegetatif Tanaman Buah. World Agroforestry Centre (ICRAF) dan Winrock International. Bogor.

Yunita, R. 2011. Pengaruh Pemberian Urine Sapi, Air Kelapa, Dan Rootone-F Terhadap Pertumbuhan Setek Tanaman Markisa (Passiflora Edulis Var. Flavicarpa).

Zuryanisa. 2006. Pengaruh Panjang Dan Bentuk Potongan Pangkal setek Terhadap Pertumbuhan Semai Gamal (Gliricidia Sepium Jacq Steud.). Fakultas Kehutanan. Universitas Muhammadyah Malang 